\title{
A SURVEY OF EMPLOYERS' NEEDS FOR TECHNICAL AND SOFT SKILLS AMONG NEW GRADUATES
}

\author{
Christopher Scaffidi \\ School of Electrical Engineering and Computer Science, \\ Oregon State University, US
}

\begin{abstract}
Motivated by concern about the ability of graduates to succeed in the workforce, universities frequently conduct surveys of local and regional employers, to understand those companies' expectations. These can uncover specific needs not being addressed. Following a similar line of inquiry, prior research at Oregon State University interviewed employers, with the aim of identifying skills of concern. The current paper takes this research another step further by presenting a survey-based study aimed at quantifying the prevalence and level of employers' desire for workers who have these identified skills. Although all skills were rated as moderately useful or better, most soft skills scored higher than most technical skills. Nonetheless, three technical skills (source code versioning, testing and agile methods) scored approximately as well as the soft skills; these three technical skills, like soft skills, were cross-cutting and applicable to more than one software development context. Further survey questions revealed that employers preferred that, to the extent that students focus on building technical skill, these learning experiences ideally should involve creating software that students can use as evidence of their qualifications.
\end{abstract}

\section{KEYWORDS}

Computer science education, Software engineering education, Information technology education

\section{INTRODUCTION}

\subsection{BACKGROUND}

Software Developers Recently Graduated From College Frequently Need To Learn And Improve A Range Of Skills, Even After Obtaining Their First Jobs [1, 2, 3, 4]. While Some Gaps In Expertise Relate To Soft Skills And Associated Personal Attributes, Such As Those Related To Communication And Collaboration [1, 4], While Others Relate To Technical Skills Such As Source Code Control, Testing, And Specific Programming Languages [1, 4, 5]. Such Limitations In Recent Graduates' Abilities Can Hamper Their Comfort And Productivity [6].

Motivated By Concern About The Ability Of Graduates To Succeed In The Workforce, Universities Frequently Conduct Surveys Of Local And Regional Employers, To Understand Those Companies' Expectations. These Can Uncover Specific Needs Not Being Addressed. For Example, Research In The United Kingdom Found That Web-Based Programming Skills Were Of High Importance [7], Research With North Dakota State University's Employer Contacts 
International Journal of Computer Science, Engineering and Information Technology (IJCSEIT), Vol.8, No.5/6, December 2018

Revealed The Need For Students To Do More Realistic Projects Before They Graduated [8], Research In Australia Highlighted The Need For More Business-Related Knowledge [9]. The Mismatch Between Identified Skills And University Curricula Has Aided In Identifying Opportunities For Improving Curricula By Creating, Expanding Or Reordering Courses [9, 10].

Following a similar line of inquiry, prior research at Oregon State University interviewed employers, with the aim of identifying skills of concern [11]. The skills revealed by these interviews covered both technical and soft skills (Table 1) and echoed many highlighted in the studies cited above. These included, for example, agile methods, the ability to collaborate, user interface design, and entrepreneurship skills.

\begin{tabular}{|c|c|}
\hline Technical/domain skills & Soft skills / attributes \\
\hline Agile methods & Ability to collaborate \\
\hline Mobile development & Ability to cope with ambiguity \\
\hline Non-relational data/big data & Learning and curiosity \\
\hline Relational databases & Passionate innovation \\
\hline Source code management & \\
\hline System administration & \\
\hline Testing and quality assurance & \\
\hline User interface design & \\
\hline Web development & \\
\hline \multicolumn{2}{|c|}{ Business \& entrepreneurship } \\
\hline
\end{tabular}

Table 1: Skills and attributes identified as important by employers in prior interviews [11]; business skills are listed below as domain-specific yet non-technical from the standpoint of CS

\subsection{STUDY OBJECTIVES}

The current paper takes this research another step further by presenting a survey-based study aimed at quantifying the prevalence and level of employers' desire for workers who have the skills listed in Table 1.

Three research questions framed the study:

- RQ1: What preferences do employers have about new hires' educational attainment in computer science?

- RQ2: What skills do employers value most highly among future hires from computer science?

- RQ3: What forms of evidence do employers find most useful for evaluating students and graduates?

\subsection{ORganization}

Section 2 presents materials and methods, while Section 3 summarizes results. Section 4 discusses key findings from the data, which Section 5 juxtaposes with related work. Finally, Section 6 summarizes conclusions as well as focal points for future work aimed at enhancing our university curriculum in order to better meet employers' hiring needs. 
International Journal of Computer Science, Engineering and Information Technology (IJCSEIT), Vol.8, No.5/6, December 2018

\section{Materials And Methods}

\subsection{SURVEY SCOPE}

A survey was deployed to obtain data for answering the three research questions (Section 1). Participants were recruited with emails sent to a list of employers and former graduates who had previously indicated a desire to participate in research regarding software engineering education and corporate hiring. The email contained a link to the survey, deployed on the Qualtrics platform.

The survey contained 29 questions organized into 3 sections. The first invited participants to rate their likelihood of hiring students and graduates in computer science with specific educational attainment (e.g., Master's degree). The second section asked participants to rate the usefulness of technical and soft skills (e.g., SQL/database skills and writing skills); these were selected directly from the list of skills mentioned by employers in the earlier interviews [11], with the exception of "ability to communicate well" which was separated into two skills for this survey as "ability to communicate verbally" and "ability to communicate in writing." The third section had participants rate how useful they found different kinds of items for evaluating applicants who had a background in computer science (e.g., resume, transcript, source code). Throughout all three sections, each question presented a 5-level Likert scale.

\subsection{ANALYSIS}

Data for each question were summarized two different ways. First, the proportion of non-missing answers at the two highest levels the Likert scale was computed (i.e., the proportion of responses that essentially agreed with the item presented). Second, the average of non-missing answers was computed to generate an average rating for each question.

These per-question statistics were then compared in order to answer the research questions. For example, to answer RQ2, ratings for different skills were compared with one another (e.g., $\mathrm{SQL} /$ database versus writing skills, versus the other skills considered). Formal statistical tests were not conducted, due to the high risk of Type I error (there were 16 different skills, for example, posing difficulties in comparing all of them to one another) as well as Type II error (as, with 26 respondents, statistical power was low). Instead, the two summary statistics mentioned above were sorted and plotted on a bar chart in order to reveal unmistakable visual trends. These trends could be used to generate statistical hypotheses for testing in future research. The Discussion (Section 4) compares results to those from the interviews that motivated the survey, helping to triangulate and confirm conclusions.

\section{RESUlts}

\subsection{What Preferences do Employers Have about New Hires' edducational ATtainment In COMPUTER SCIEnCE?}

The survey asked respondents to rate how likely their companies were to hire students from six different categories that varied by educational attainment. These ranged from hiring Bachelor's 
students as interns prior to graduation all the way to graduates who had obtained a $\mathrm{PhD}$. The responses showed two clear trends.

First, for each of the three degrees, the likelihood of hiring graduates exceeded the likelihood of hiring students for internships prior to graduation. These trends appeared in both the proportions reporting they were likely to hire students of each category (Fig. 1) and the average rating of likelihood (Fig. 2).

Second, the likelihood of hiring students generally decreased with rising level of educational attainment. Respondents were relatively unlikely to hire $\mathrm{PhD}$ students (either before or during graduation), relatively more likely to hire Master's students, and the most likely to hire Bachelor's students. At the low end, only $21 \%$ of respondents were likely or definitely intending to hire $\mathrm{PhD}$ students for internships. At the high end, $88 \%$ indicated the same for students who had graduated with a Bachelor's degree.

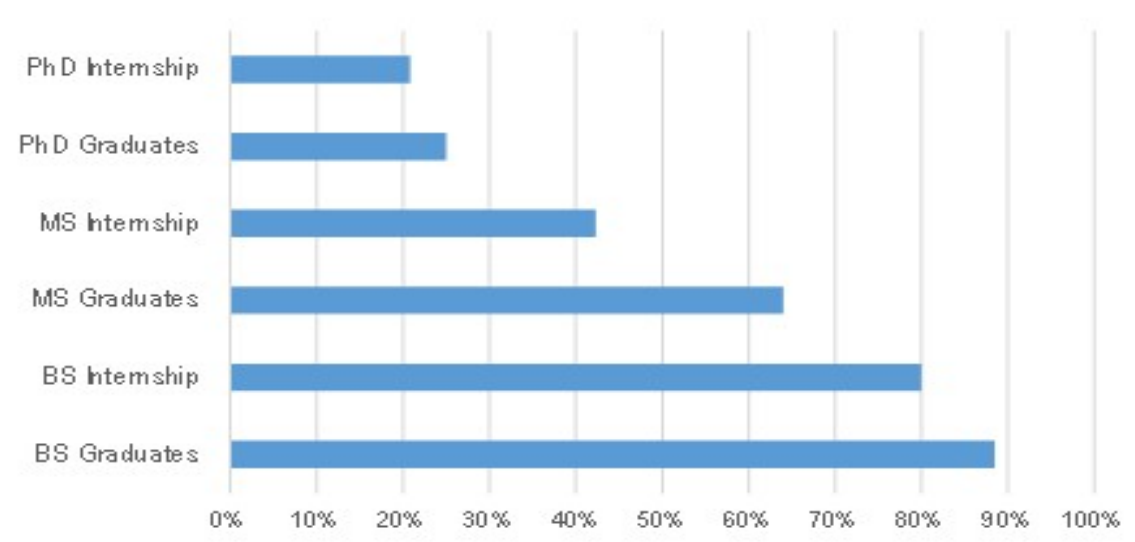

Fig. 1: Proportion of respondents who were likely or definitely going to hire students in the next 5 years, by degree (Bachelor's, Master's, or $\mathrm{PhD}$ ) and by graduation status (after graduation, or as an intern before graduation).

\subsection{WHAT SKILLS DO EMPLOYERS VALUE MOST HIGHLY AMONG FUTURE HIRES FROM COMPUTER SCIENCE?}

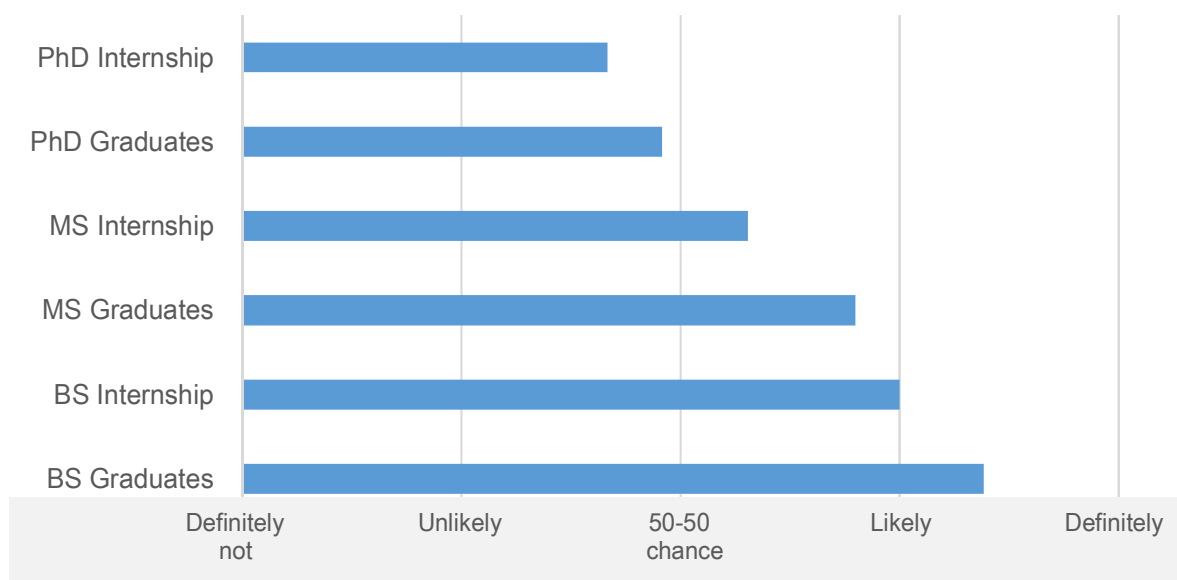

Fig. 2: Average estimated likelihood of hiring students in the next 5 years 
Respondents rated the usefulness of 7 soft skills and attributes as well as 10 technical skills. Plotting the proportion rating each skill as very or extremely useful (Fig. 3), and plotting the average rating of each skill (Fig. 4), revealed three trends.

First, all skills were rated on average at least as moderately useful. The lowest-rated was the business/entrepreneurship soft skill, which only $50 \%$ considered very or extremely useful. At the high end, $100 \%$ of respondents considered a hire's drive to learn as very or extremely useful. This result suggests that the collection of skills for the survey, based on prior interviews [11], was well-chosen.

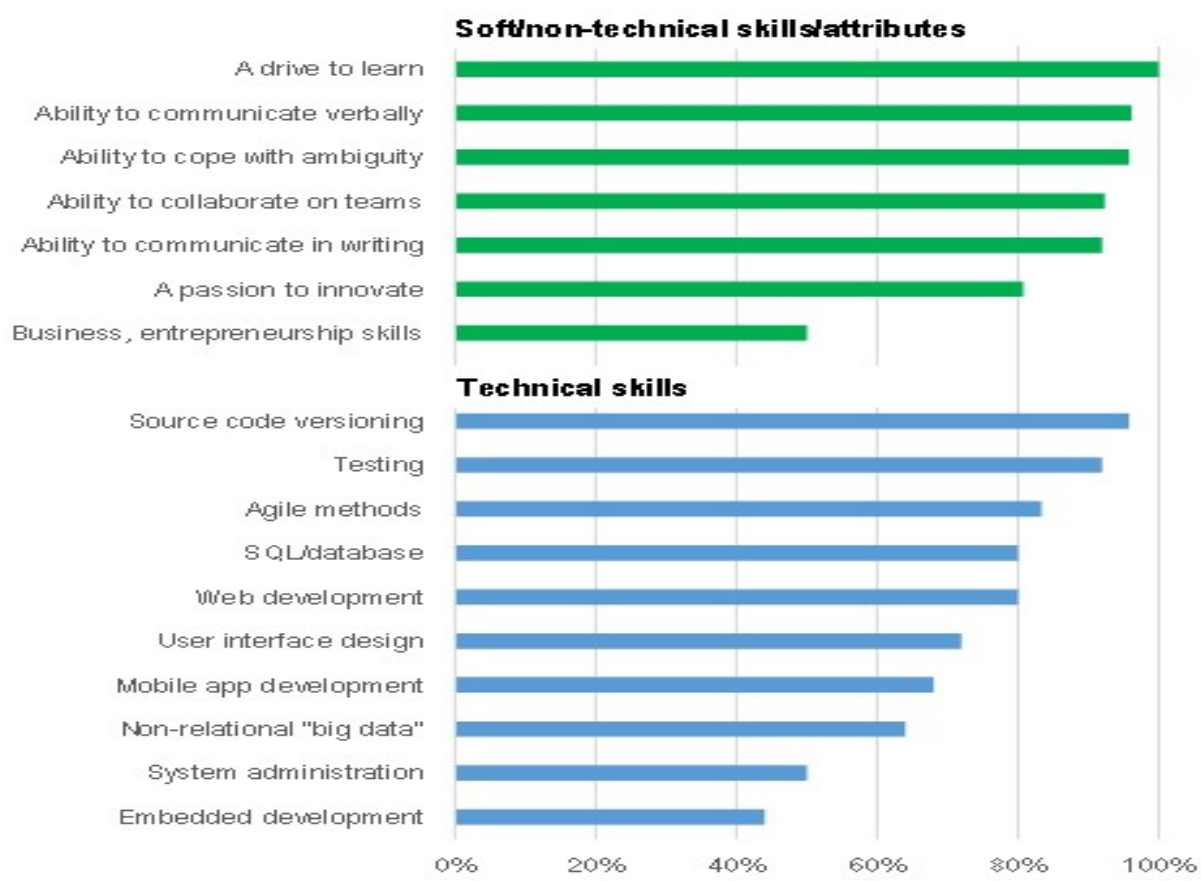

Fig. 3: Proportion of respondents who indicated that specific skills and attributes were very useful or extremely useful.

Second, almost all soft skills/attributes were more highly valued than almost all technical skills. All but one of the soft skills/attributes were rated as very or extremely useful by at least $80 \%$ of respondents, the average rating across all 7 soft skills was 3.44 (between very and extremely useful). In contrast, only half of the technical skills were rated as very or extremely useful (source code versioning, testing, agile methods, SQL/database, and web development). The average rating of among all technical skills was only 2.95 (slightly below very useful). 


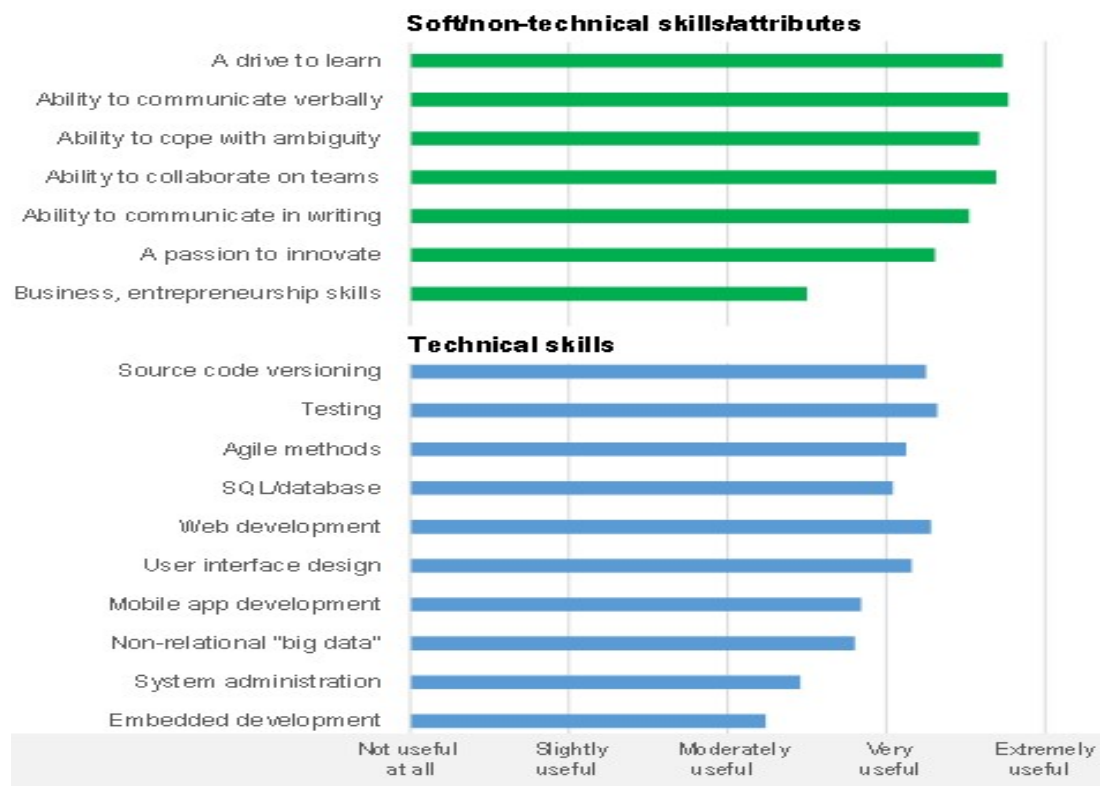

Fig. 4: Average ratings of the usefulness of soft skills/attributes and technical skills.

Third, all 3 of the top-rated technical skills were, in some sense, cross-cutting and applicable to more than one software development context. These 3 skills were source code versioning, testing, and agile methods. All of these can be applied in the context of web development, mobile app development, embedded development, and many other contexts (e.g., desktop software development, cloud development, etc.) not specifically examined in this survey. The result may imply that generalizable technical skills are viewed as more useful than skills targeted to specific development contexts.

\subsection{WHAT FORMS OF EVIDENCE DO EMPLOYERS FIND MOST USEFUL FOR EVALUATING STUDENTS AND GRADUATES?}

Respondents rated the usefulness of 6 items that job applicants may present as evidence of their qualifications related to computer science. The results revealed two trends (Figs. 5, 6).

First, school-centric items were generally considered of little or no usefulness. Transcripts were rated as only slightly more than moderately useful, and only $25 \%$ of respondents considered transcripts to be very or extremely useful. Even references-which, for a student or recent graduate, might generally just include professors-fared only slightly better, at $40 \%$ of respondents and a still only slightly-above-moderate level of usefulness. The resume scored higher, nearly attaining a rating of "very useful."

Second, items related to making software were generally considered of high usefulness. With a rating of very or extremely useful by $92 \%$ of respondents, the highest-rated was source code, which to be precise, the survey described as "Source code (e.g., via github) that the applicant wrote." The next highest was "Software (e.g., apps, websites) that the applicant made," which was rated as very or extremely useful by $88 \%$ of respondents. The only software-centric item that obtained a low score was "Screenshots, videos of applicant's past work," which obtained ratings between transcripts and references. 
International Journal of Computer Science, Engineering and Information Technology (IJCSEIT), Vol.8, No.5/6, December 2018

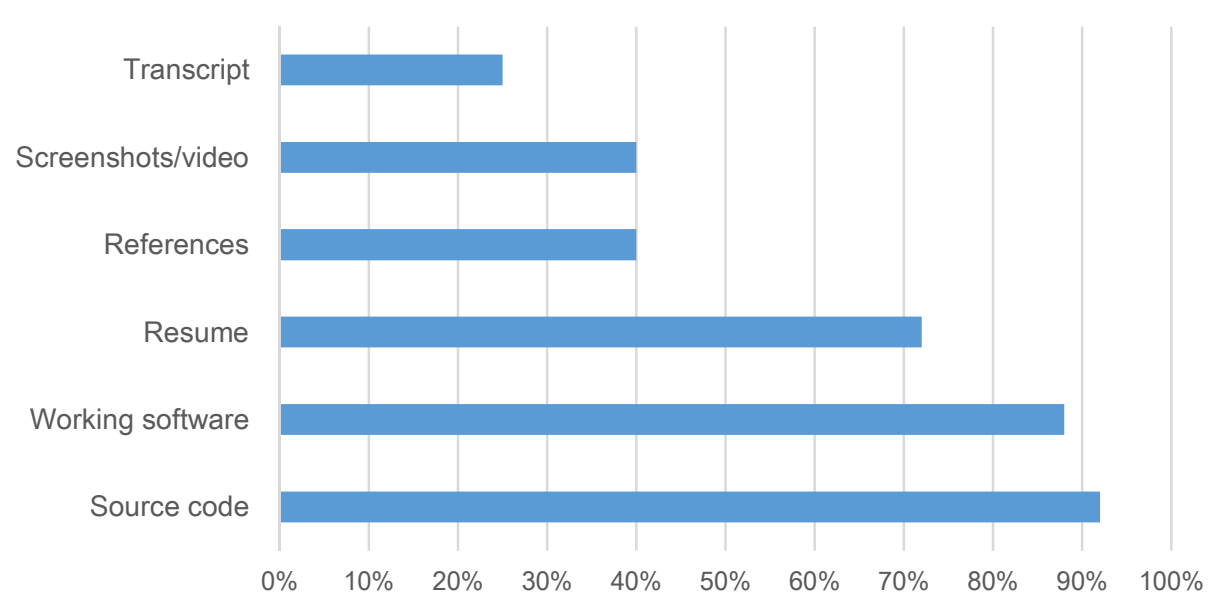

Fig. 5: Proportion of respondents that considered each item to be very useful or extremely useful as evidence of applicants' qualifications.

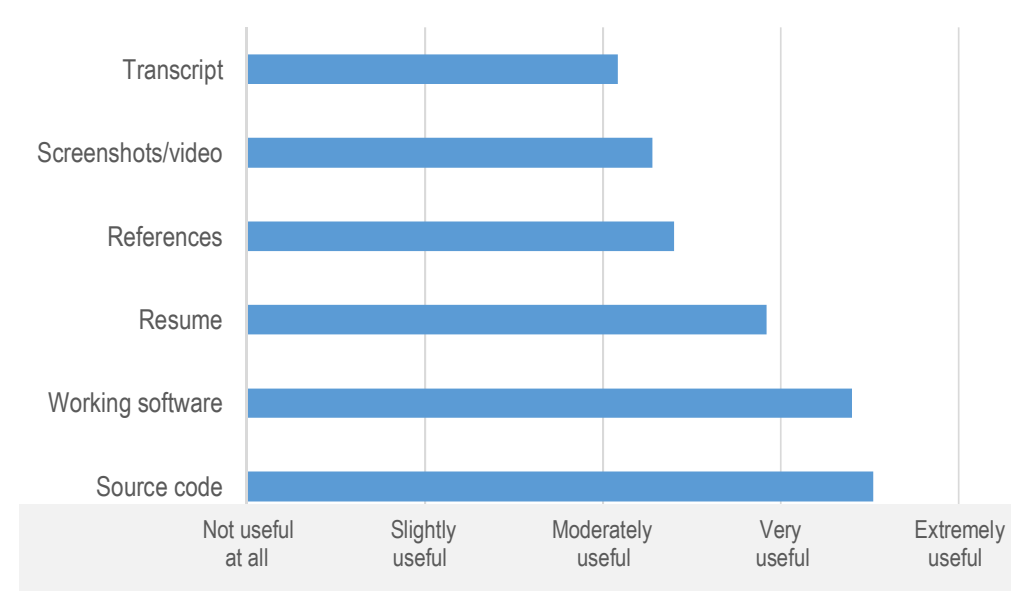

Fig. 6: Average ratings of each item as evidence of an applicant's qualifications.

\section{Discussion}

The results address the research questions that motivated this work.

RQ1: What preferences do employers have about new hires' educational attainment in computer science? On the whole, respondents showed a consistent higher preference for graduates with relatively lower degree status (Bachelor's, Master's, $\mathrm{PhD}$ ) and for graduates over interns.

RQ2: What skills do employers value most highly among future hires from computer science? Although all skills were rated as moderately useful or better, most soft skills scored higher than most technical skills. Nonetheless, 3 technical skills scored approximately as well as the soft skills (source code versioning, testing and agile methods), all which-like soft skills-were cross-cutting and applicable to more than one software development context. 
International Journal of Computer Science, Engineering and Information Technology (IJCSEIT), Vol.8, No.5/6, December 2018

RQ3: What forms of evidence do employers find most useful for evaluating students and graduates? School-based evidence generally obtained low scores, and evidence related to actual project work generally obtained the highest.

The results for the first two research questions suggest employers may be most interested in finding entry-level employees with strong aptitude and desire to learn, whom they can train and develop in a specific technical direction pertinent to the company's needs. This inference dovetails with results from the prior interviews of employers [11], almost all of whom indicated wanting workers with a drive to learn. They mentioned phrases like "lifelong learners," "curiosity," and "drive." Some interviewees also explicitly said that applicants' specific language and platform experience mattered relatively little because it was relatively easy for developers experienced with one to pick up another.

Survey and interview respondents both very strongly emphasized the need for soft skills. One interviewee highlighted the relative importance of soft skills over technical skills by stating, "We do not value people sitting at their desk and writing code all day." In particular, all but one interviewee emphasized the importance of communication skills; the survey results provide more fine-grained insight into what this means, in that verbal and writing communication skills were both rated as highly important.

The results for the third research question are striking in terms of highlighting the emphasis that employers place on whether students and recent graduates can demonstrate experience with actual software development tasks. Transcripts, references and screenshots do not necessarily provide such insight: course grades might primarily be based on exam scores, faculty who serve as references might primarily emphasize such grades rather than project work, and screenshots offer only a static impression of software and little insight into the process of its creation. In contrast, a well-written resume can discuss how software was built, a working app or website can serve as the focus of interview questions about the software's creation, and source code reveals the internals of the software's construction.

The emphasis on real experience with the process of creating working software also manifested in interview results [11]. Several interviewees emphasized the importance of using tools and design patterns in academic training that matched those used in industry, and three specifically noted the importance for applicants to tell stories about past projects in ways that demonstrated knowledge and expertise. One of them explicitly said they only wanted workers capable of "thinking beyond homework assignments," emphasizing the potential disconnect between academic work and realworld practicable skills.

\section{RELATED WORK}

Numerous studies have reported that recent graduates lack certain skills that they must master while on the job (e.g., [1, 2, 3, 4]). For example, based on a literature survey of empirical studies, Radermacher and Walia determined that the most-often mentioned gap in new workers' skills existed in the area of written communication [1]. Other oft-cited weaknesses included oral communication, project management and teamwork. All these are soft skills, consistent with the results of the current survey, which revealed the importance of training students in soft skills. 
International Journal of Computer Science, Engineering and Information Technology (IJCSEIT), Vol.8, No.5/6, December 2018

Moreover, Radermacher and Walia noted several lacking technical skills, including in the areas of software tools, testing and programming. These skills are cross-cutting, again consistent with the results of the current survey. Unlike the current survey, Radermacher and Walia did not mention the importance of source code control or specific programming languages, although those have appeared in lists of necessary skills generated by other studies (e.g., [4, 5]).

Unlike the studies cited above, the current survey also investigated what forms of evidence about skills are sought by employers. This has been a topic of concern in a handful of other studies (e.g., $[12,13,14])$. For example, Marlow and Dabbish interviewed members of the GitHub "social coding" community to investigate the extent to which accounts on that site facilitated hiring and recruitment of software developers [12]. They found that potential employers tended to focus on how frequently and consistently programmers committed work to online project repositories, as well as how well networked programmers were (e.g., through having followers, having submitted pull requests, and having interacted with others on the site). In fact, interviewees stated that they relied upon these signals when judging candidates' skills even more strongly than they relied upon information written in resumes - consistent with findings from the current survey. Likewise, a survey of employers found that they do value open source projects reported on a resume, as long as the development practices reflected in those projects are compatible with the processes used at each employer [14].

\section{Conclusions And Future Work}

\subsection{Conclusions}

In short, this study has provided additional insight into what it means to train work-ready graduates, with an emphasis noted above on development of soft skills and manifestation of technical skills in actual source code and working software.

The findings of prior studies (Section 5) are consistent with those of the current study, which also adds to the literature by providing quantitative evidence about the relative importance of different evidence signals. In particular, as shown in Figures 5 and 6, the current survey revealed a clear progression of importance: evidence from the abstract academic setting (e.g., transcripts) was least persuasive, descriptive evidence of prior work (e.g., references and resume) was moderately persuasive, and direct concrete materials derived from project work (e.g., working software and source code) was most persuasive.

Taken together, all the results from the survey and the interviews suggest that training work-ready graduates involves cultivating a drive to learn and other soft skills/attributes at least as much as it involves giving students technical skills. Advanced degrees, such as the Master's and $\mathrm{PhD}$, in particular, are at risk of providing little additional value unless if they reinforce these skills and attributes. And, to the extent that students at all levels build technical skill, they should do so in a way that manifests expertise through practical experiences creating software that they can use as evidence of their qualifications.

\subsection{SCOPE OF POTENTIAL FUTURE WORK}

Future work could build on this research in several areas. 
International Journal of Computer Science, Engineering and Information Technology (IJCSEIT), Vol.8, No.5/6, December 2018

First, a larger survey involving more employers could address the threats to validity entailed by the small sample size of the current study. The sample size prevented use of statistical tests to confirm trends observed in the data, so the findings above, while visually salient, might not actually be significant. Moreover, obtaining demographic data about respondents (e.g., company size and target markets) could aid in ascertaining the extent to which any sampling and/or nonresponse bias limits generalizability. Additional questions that go beyond opinions and ask about historical facts (e.g., asking about students hired by the company in the past) could aid in further triangulation and establishing aspects of internal validity. The results of this survey provide insights for interesting focal points of future surveys rather than definitive conclusions.

Second, the results suggest directions for additional work aimed at enhancing the university curriculum. For example, a review of the curriculum could be done in order to assess the extent to which courses aid in developing soft skills, as well as whether syllabi provide for students to engage in learning activities that lead to working software that they could use as evidence of their qualifications. In addition, students who already have graduated could be invited into the classroom to talk about what projects they did, during their time as students, that proved most useful for convincing employers to hire them. Additional research could measure the extent to which such guidance prompts students attempt to put this guidance into practice, the extent to which they succeed, and whether these projects do in fact lead to impacts on employment obtained immediately after graduation.

Finally, future work could follow up on the fact that, among all the skills and attributes rated by respondents, the passion to learn was valued most highly. One interviewee in the prior study explicitly contrasted this with the "I don't care" attitude all too common among recent graduates, and other interviewees noted the difficulty of finding workers with a drive to learn. This is disappointing, particularly considering the role that universities play in preparing students for career success. Additional studies could aim to understand what instructional experiences help to nurture and amplify this drive - as well as what instructional experiences quench it. Research would clearly be valued on how to stimulate not only students' immediate motivation to learn within a given course, but also how to cultivate a passion for lifelong learning.

\section{REFERENCES}

[1] Radermacher, A., and Walia, G. (2013) Gaps between industry expectations and the abilities of graduates. ACM Technical Symposium on Computer Science Education, 525-530.

[2] Exter, M. (2014) Comparing educational experiences and on-the-job needs of educational software designers. ACM Technical Symposium on Computer Science Education, 355-360.

[3] Lethbridge, T. (2000) What knowledge is important to a software professional? IEEE Computer. 33(5), 44-50.

[4] Begel, A., and Simon, B. (2008) Struggles of new college graduates in their first software development job. ACM SIGCSE Bulletin, 226-230

[5] Lethbridge, T. (2000) Priorities for the education and training of software engineers. Journal of Systems and Software. 53(1), 53-71.

[6] Begel, A., and Simon, B. (2008) Novice software developers, all over again. International Workshop on Computing Education Research, 3-14. 
International Journal of Computer Science, Engineering and Information Technology (IJCSEIT), Vol.8, No.5/6, December 2018

[7] Kitchenham, B., Budgen, D., Brereton, P., and Woodall, P. (2005) An investigation of software engineering curricula. Journal of Systems and Software. 74(3), 325-335.

[8] Radermacher, A., Walia, G., and Knudson, D. (2015) Missed expectations: Where CS students fall short in the software industry. CrossTalk: The Journal of Defense Software Engineering. 28(1), 4-8.

[9] Amiri, A., Banari, M., and Yousefnezhad, N. (2011) An investigation of undergraduate software engineering curriculum: Iranian universities case study. IEEE International Conference on Computer Science \& Education, 638-644.

[10] Hanna, S., Jaber, H., Jaber, F., Al Shalaby, T., and Almasalmeh, A. (2014) Enhancing the software engineering curriculums: A case study of the Jordanian universities. IEEE Conference on Software Engineering Education and Training, 84-93.

[11] Scaffidi, C. (2018) Employers' needs for computer science, information technology and software engineering skills among new graduates, International Journal of Computer Science, Engineering and Information Technology, 8(1), 1-12.

[12] Marlow, J., and Dabbish, L. (2013) Activity traces and signals in software developer recruitment and hiring, Conference on Computer-Supported Cooperative Work, 145-156.

[13] Marlow, J., Dabbish, L., and Herbsleb, J. (2013) Impression formation in online peer production: Activity traces and personal profiles in GitHub, Conference on Computer-Supported Cooperative Work, 117-128.

[14] Long, J. (2009) Open source software development experiences on the students' resumes: Do they count? Journal of Information Technology Education, (8)1, 229-242.

\section{AUTHOR}

Christopher Scaffidi earned a Ph.D. in software engineering from Carnegie Mellon University and is currently an associate professor of computer science in the School of EECS at Oregon State University. His research interests are where human-computer interaction and software engineering intersect. Most of his current projects aim to help software users to create code for themselves, and to

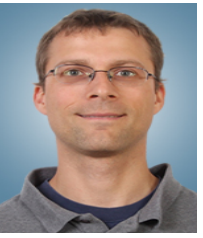
effectively share that code with one another. 